\title{
When red tape saves time: The Anti-corruption controls for the 2015 Universal Exposition
}

Simone Busetti and Bruno Dente

\section{(2) OpenEdition \\ Journals}

Electronic version

URL: https://journals.openedition.org/irpp/1608

DOI: 10.4000/irpp.1608

ISSN: 2706-6274

Publisher

International Public Policy Association

\section{Printed version}

Date of publication: 15 March 2021

ISSN: 2679-3873

\section{Electronic reference}

Simone Busetti and Bruno Dente, "When red tape saves time: The Anti-corruption controls for the 2015 Universal Exposition", International Review of Public Policy [Online], 3:1 | 2021, Online since 15 March 2021, connection on 17 June 2021. URL: http://journals.openedition.org/irpp/1608 ; DOI: https://doi.org/10.4000/irpp.1608

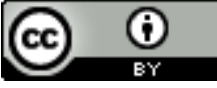




\section{When red tape saves time: The Anti-corruption controls for the 2015 Universal Exposition}

\section{Simone Busetti}

Università degli Studi di Teramo, Italy

\section{Bruno Dente}

Politecnico di Milano, Italy

\section{Abstract}

When a major corruption scandal emerged during the organisation of the 2015 Universal Exposition in Milan, the government set up a brand-new system of preliminary controls for the procurement of all Expo contracts. Controls can certainly be beneficial in many respects, but they inevitably complicate procedures and even produce delays and red tape. Indeed, for a time-pressed schedule as that of the 2015 Expo, preliminary controls were considered a fatal blow. Contrary to expectations, not only bureaucratic delays did not materialise, but controls actually sped up procedures. Therefore, it is worth explaining and learning from this unique outcome. Can it be replicated in other cases? We answer this question by building a model of controls based on programme and non-programme features that support three causal mechanisms: threat attribution, repeated interactions, and actor certification. Such a model is an indispensable tool for designers; it allows to explain how controls work in practice and provide clues on how to adjust the design of the policy to changing contexts. In this respect, the analysis of the Expo controls and their subsequent replications raises several methodological issues relevant to extrapolation-oriented research.

\section{Keywords}

policy design, causal mechanism, learning, extrapolation 


\section{Introduction}

Hosting mega-events, such as world fairs, football championships, or the Olympics, is highly prized by policymakers. Mega-events are promoted as opportunities for triggering radical changes in the political, economic, and urban agendas (Stevens \& Bevan, 1999; Kang \& Perdue, 1994; Spilling, 1996; Bramwell, 1997). However, the planning and implementation of such events have received several critiques (Gursoy \& Kendall, 2006). Hallmark events are characterised by time pressure, fast-track decision making, the suspension of ordinary administrative procedures, and an overall lack of transparency (Pillay et al., 2010). In combination with exceptional public spending, rushing administrations, and special procedures, opportunities for corruption are a typical concern for such events.

The organisation of the Universal Exposition of Milan seemed to fit this picture perfectly. In May 2014, only one year before the opening of the Expo, a major corruption scandal hit the news. Together with five other people, the procurement director of the Lombardy Region and the procurement manager of Expo Ltd.-the contracting authority and organising company of the Expo-were arrested. The main accusation involved a 55-million-euro contract for all service infrastructures on the event site-restaurants, toilets, storage rooms, and personnel offices. In addition, there were allegations of an organised criminal group able to manipulate all the Expo 2015 bids (Biondani \& Gatti, 2014).

In response, the government introduced a new system of preliminary controls regarding all procurement documents issued by Expo Ltd. The company had to send all draft documents to the Italian Anti-corruption Agency (ANAC), where a Special Operative Unit (hereafter the Unit) would control the documents and possibly produce observations on legal issues and irregularities. The observations were not binding but were nonetheless a serious complication of the Expo procurement: instead of issuing all documents on its own, Expo Ltd. had to wait for the ANAC to produce their observations and then either redraft the document accordingly or respond with counter-observations (see Figure 1).

This relationship between controls and administrative costs is well-known in the literature. While increasing transparency and accountability, corruption controls may lead to delays, controversy (Rose-Ackerman \& Palifka, 2016), and even red tape and other bureaucratic pathologies (Anechiarico \& Jacobs, 1998). From the perspective of Expo Ltd, the new procedures were indeed a case of stakeholder red tape; rules that entail a compliance burden and do not serve the organisational purpose of the company (Bozeman, 1993). In such cases, resources and personnel are absorbed by rule compliance and this typically produces inefficiencies in the form of task delays in performing core functions (Bozeman, Reed \& Scott, 1992; Pandey \& Scott 2002). Further, the introduction of external checks, additional decision makers and veto points is likely to contribute to lengthening time (Tsebelis, 2002).

Surprisingly, however, these administrative costs did not materialise in the case of the Expo. On the contrary, all the observers-policy makers, the ANAC, Expo Ltd., and Expo managers-agreed that controls actually sped up the Expo procurement. Interestingly, this happened in a case that was highly contentious. The Expo was a matter of conflict between the municipal and regional governments from the day after winning the bid, and several actors were eager to use corruption scandals to prove their case against the mega-event. Notwithstanding conflict and the special watch by all opponents, the burdened procedures sped up procurement. The perception of success was so great that controls were quickly replicated and eventually became institutionalised in 2016 under the name of 'collaborative surveillance'. 
The aim of the paper is to explain this unique result and discuss the possibility of learning from this experience. The next section presents our methodology, inspired by extrapolation-oriented methods. The third section describes the administrative procedures entailed by the controls and provides additional data on their success. In the fourth section, we attempt to explain these surprising results and build a causal model of controls based on three mechanisms: the attribution of threat, repeated interactions, and actor certification. The fifth section discusses the replicability of this seemingly unique experience with respect to applying the same procedure to new contexts.

\section{Methods: Mechanisms and extrapolation}

Extrapolation is a major issue in both social and hard sciences (Steel, 2007). In 2004, Eugene Bardach raised scholarly attention to the 'extrapolation problem' and suggested to search for the causal mechanisms underlying policy success. This was considered a possible strategy to overcome the limits of 'best practice research' and avoid bad replications caused by formal duplications of designs, disregarded causal features, and the copy of useless details. Drawing on Bardach's suggestions, Barzelay (2007) proposed the use of 'extrapolative case-studies' aimed specifically at identifying those design and context features that trigger and support the causal mechanisms. The article follows this approach and focuses on those causal mechanisms that explain the implementers' behaviour and cooperation (Busetti \& Dente, 2018). We limit this section to three features of the mechanism-based analysis that are worth mentioning here: the nature of the mechanisms, their possible 'activators' (Capano et Al. 2019, Capano \& Howlett 2019), and the level of abstraction.

First, mechanisms are causal theories-i.e., theoretical constructs that explain how initial conditions produce outcomes. The use of labels is recurrent in the literature-e.g., blame avoidance (Barzelay, 2007), brokerage (McAdam et al., 2001), or naming and shaming (Pawson, 2002)_and we use labels as a way to quickly grasp the inherent causal logic. However, labels are not necessary. The key issue is to provide a deeper understanding of causality and a more finegrained specification of the causal paths (see Hedstrom \& Swedberg, 1998; Mahoney, 2003; Mayntz, 2004; Gerring, 2010). As for theory-based approaches to evaluation (Chen, 1990), the research on mechanisms is focused on why and how a policy works and not on its impact.

Second, mechanisms are 'sets of interacting components' (Steel, 2008, p. 41). They are triggered and supported over time by a relatively stable configuration of factors, including both design and context features. Policy programmes contribute to the outcome to some extent, although they are not the only ones responsible for programme results (Mayne, 2012). Therefore, if context-dependency is more of a rule than an exception (Franzese, 2007), our causal theoretical framework needs to model context features as well. In the remainder of the article, we will use the term programme features for all the elements that were designed for the programme (not only policy tools but also elements such as implementation devices or resources) and non-programme features for all those elements that occur in the case incidentally (such as media attention or a specific level of administrative capacity).

Third, learning from a unique experience requires abstracting from the case. Rose (1993) considered the construction of a causal model of a programme (i.e., a configuration of factors) as a preliminary step to learning from practices and transfer lessons. Such a model would abstract cause-and-effect relations among programme and non-programme elements and their effects beyond the idiographic description of the case. In fact, this process of abstraction is a fundamental step to design functional equivalents; i.e., design elements that differ from the original 
case but help trigger and support the same causal mechanisms. The identification of mechanisms in Section 4 is an effort to provide such an abstraction, while the analysis of possible replications in Section 5 attempts a discussion on functional equivalents.

The collaborative controls in the case of the Expo can be classified as a 'deviant case'; i.e., a case that presents surprising values and may be used to probe for new explanations and be applied to other cases (Gerring, 2006). Although we do not provide a formal application, the research strategy follows the procedures of 'explaining outcome' process tracing (Beach \& Pedersen, 2019). We started with the outcomes in need of an explanation, reconstructed the causal process conducive to those outcomes and provided evidence on the elements triggering and supporting the mechanisms. This is a theory-generation case study, where mechanisms were reconstructed by working iteratively from empirical results to hypotheses building.

The case material includes diverse sources, complementing the analysis of official documents with newspaper articles and other media. Together with several exploratory interviews on the Expo, six additional semi-structured interviews were conducted specifically for this case study and are listed in the Appendix.

\section{Collaborative controls and unexpected results}

Legislation 90/2014 introduced a new system of ex-ante controls to be performed by a newly established Special Operative Unit for Expo 2015 (hereafter, the Unit) within the ANAC. The members of the Unit are not administrative officials of the ANAC but military personnel. The Unit includes three officers and a colonel belonging to the Financial Police and responding directly to the President of the ANAC. The members of the Unit are also not common bureaucrats; they have access to criminal records and other information unavailable to administrative officials and they use investigative methods when performing controls.

The controls required the contracting authority (Expo Ltd.) to send the Unit all draft procurement documents for contracts over $€ 40,000$ : instructions to tenders, technical specifications, the appointment of evaluation committees, the assessment and award of tenders, and documents related to contract implementation and modification. Before publishing any such documents, Expo Ltd. had to submit them to the Unit, which examined the documents and produced advice that could include observations on both legal issues and irregularities. The observations on procurement documents were due within 7 days, whereas those on contract implementation within 15 days (see Figure 1 ). 
Figure 1: The procurement process of Expo Ltd. before (A) and after (B) the introduction of collaborative surveillance
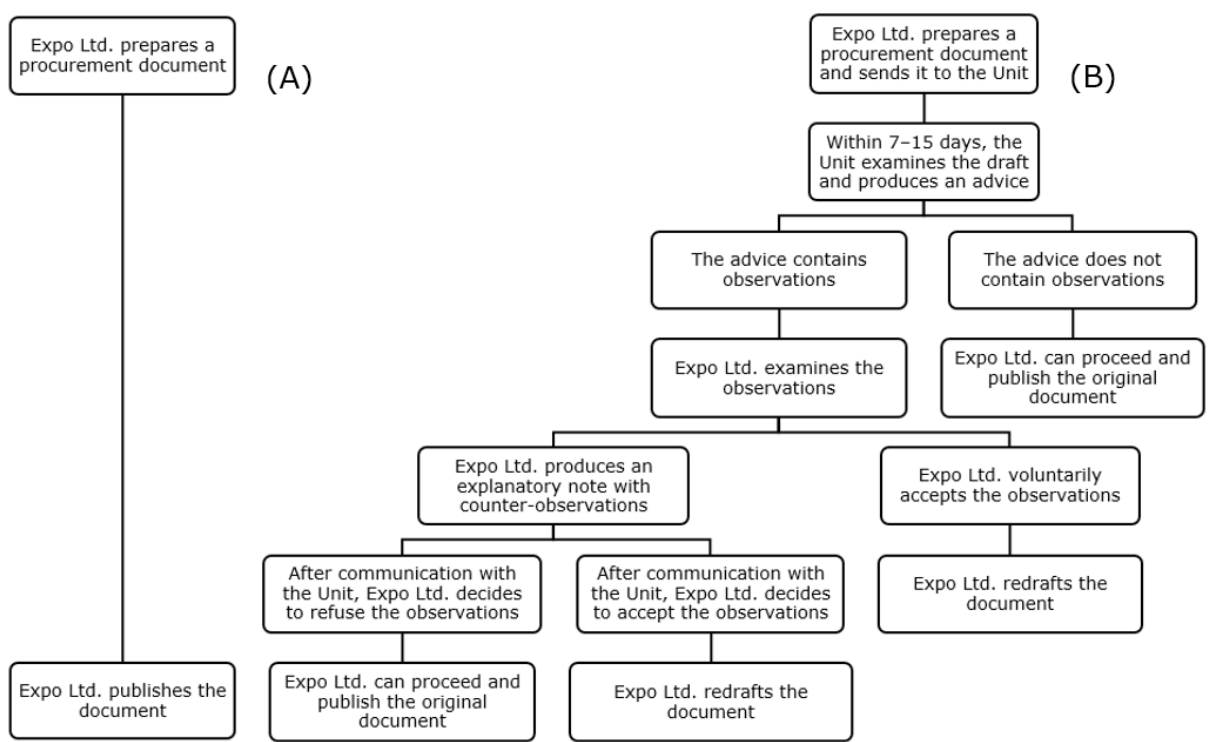

\section{Source: The Authors}

As mentioned, the observations were not binding. Expo Ltd. could ignore them but had to produce an explanatory note motivating its conduct through counter-observations. Following the explanatory note, the Unit and Expo Ltd. could start a dialogue conducing to either the refusal or the acceptance of the observations. In the latter case, Expo Ltd. had to redraft the document as if accepting the observations voluntarily.

Figure 1 allows us to appreciate the size of procedural complication introduced with respect to a former system where Expo Ltd. had no ex-ante controls at all. Indeed, collaborative surveillance meant a complete U-turn in the Expo procurement: from special procedures aimed at simplification and rapidity to procedures more complicated than the ordinary.

Notice also that when the controls were imposed, the delays on the works were substantial. Only $40 \%$ of the basic infrastructure of the Expo site (the one where pavilions were to be built) (Luongo, 2019, p. 7) and 10\% of the works for the contract of service infrastructures (Special Commissioner for the service infrastructures of the Expo, personal communication, December 15, 2016) had been completed at that time. Moreover, Expo Ltd. had yet to sign about one thousand contracts for acquiring goods and services (http://dati.openExpo2015.it/it). In this context, all media predicted an unfinished Expo, a complete failure, and a huge international embarrassment (e.g., Barbacetto \& Maroni, 2015; Poletti, 2015; Verdelli, 2015a; Monaci, 2014).

In this difficult situation, Expo Ltd. perceived the introduction of controls as a fatal blow to the implementation of the Exposition (Expo Ltd. Procurement Manager, personal communication, November 18, 2016). Involved by the ANAC for monitoring the new system of controls, the OECD also had to admit the risk: 'the ex-ante control of documents [...] by a party separate 
from the contracting authority, could exacerbate the time it takes to complete tenders' (OECD, 2015 a, p. 3). Confronting the diagram in Figure 1 with the former procedure-the simple draft and publication of procurement documents by Expo Ltd.- - gives a measure of the amount of risk.

Against these predictions, the Expo opened on time. Most surprisingly, the introduction of controls was considered part of the implementation's success. As mentioned, all actors involved shared a similar view, that the controls did not only increase transparency but also sped up procurement procedures (Expo Ltd. Procurement Manager, personal communication, November 18, 2016; Members of the Special Operative Unit, personal communication, October 25, 2016 and January 5, 2017; President of the ANAC, personal communication, October 10, 2016). In the scientific papers by the ANAC, the system is said to have allowed for a greater speed of procurement, a drastic reduction of appeals and litigations, an increased quality of the procurement documents, and an overall increase in the efficiency of the working procedures of the contracting authority (Luongo, 2019, pp. 22-32). In October 2015, the OECD and the ANAC produced a document called 'High Level Principles for integrity, transparency and effective control of major events and related infrastructures' (OECD, 2015c). The document made an evaluation of the collaborative controls and judged it as an exemplary practice. In fact, the model was part of the OECD recommendations for the construction of the new international airport in Mexico City (OECD, 2015d), a model which was actually implemented by the Mexican government (OECD, 2016).

The perception of success was so widespread that from being a very special procedure invented for the Expo, collaborative controls were institutionalised in the 2016 Code of Public Procurement and were replicated several times for other delicate cases and major procurement processes, such as the Extraordinary Jubilee of Mercy in 2015-2016, the reconstruction following a major earthquake in Central Italy in 2016, and the 2019 World University Games. In addition, the ANAC elaborated a twin practice of collaborative controls performed by administrative officials (instead of the military Unit) to be activated upon the request of public administrations. This extension was so successful that the ANAC was even forced to issue tighter constraints to access the tool because too many requests were coming from administrations that wanted their contracts checked by the authority (ANAC, 2017b).

\section{The mechanisms of collaborative surveillance}

This section presents the case study and builds an explanation based on three mechanisms: threat attribution, repeated interactions, and actor certification. The three subsections that follow have the same structure: the description of the outcomes to be explained, the definition of the mechanism responsible for those outcomes, and the presentation of the programme and non-programme elements triggering and supporting the mechanism. The three mechanisms are illustrated separately for the readers' convenience, but they are to be thought of as the building blocks of a compound causal model. As will become clear, one of the mechanismsthreat attribution-is responsible for how controls were implemented (i.e., more or less efficiently), while the other two are directly related to improvements in the implementation of the Expo contracts by increasing the quality of procurement and the speed of contract execution.

\section{Threat attribution}

As mentioned, the law mandates that controls are limited to contracts over $€ 40,000$ and that advice should be produced within either 7 or 15 days depending on the kind of contracting document to be examined. The financial limits and the time thresholds are designed to avoid 
overload and excessive delays, respectively. However, the efficiency of collaborative surveillance does not lie in the way the controls are limited but in how they are implemented.

The most striking outcome to be explained is the systematic anticipation of the time threshold, with remarks communicated within 4 days on average instead of the 7-15-day legal requirement (OECD, 2015b). This was not a random result but the product of a precise strategy to increase the efficiency of controls and limit the bureaucratic burden. Both the Unit and Expo Ltd. significantly over-performed; they worked almost 24/7 and soon adopted fast communication tools (such as WhatsApp or emails) instead of using the dedicated web platform. The Unit even standardised control procedures by setting up checklists and red flags that permitted the controls to be both accurate and quickly delivered.

These behaviours were not to be expected. The ANAC is an independent authority with the only statutory goal of preventing corruption. Working hard for cutting time when controlling a company already in trouble with corruption is absolutely unexpected. Why the ANAC decided to care about not only performing controls but also avoiding red tape is worthy of investigation.

The explanation lies in the activation of the mechanism of threat attribution (McAdam et al., 2011). In this case, cooperative behaviour is adopted because a bad implementation may severely harm the implementers' self-interest (Busetti \& Dente, 2018). The mechanism can be understood as a negative incentive, wherein both the programme and non-programme features signal the importance of avoiding implementation failure. These aspects are represented in Figure 2.

Figure 2: Threat attribution

\begin{tabular}{|c|c|c|}
\hline $\begin{array}{c}\text { Programme and non-programme } \\
\text { features increase the perception of } \\
\text { threat }\end{array}$ & $\begin{array}{c}\text { Implementers behave } \\
\text { cooperatively }\end{array}$ & $\begin{array}{l}\text { Implementation } \\
\text { outcome }\end{array}$ \\
\hline $\begin{array}{ll}\text { PROGRAMME FEATURES: } \\
-\quad \text { Mandatory controls on all } \\
& \text { documents for contracts }> \\
& € 40,000 \\
\text { NON-PROGRAMME FEATURES: } & \\
- & \text { Unescapable deadline and delays } \\
- & \text { Corruption scandals and media } \\
& \text { attention } \\
- & \text { EXPO company has its own } \\
& \text { unique goal in the event } \\
& \text { implementation } \\
- & \text { ANAC and Unit first task and } \\
& \text { main test }\end{array}$ & $\begin{array}{l}\text { - Over-working } \\
\text { - Informal communication } \\
\text { - Standardisation of control } \\
\text { procedures through } \\
\text { checklists }\end{array}$ & $\begin{array}{l}\text { - Anticipation of the } \\
\text { time threshold }\end{array}$ \\
\hline
\end{tabular}

Source: The authors

The activation of this mechanism was partly intrinsic in the nature of Expo Ltd. and does not need much explanation. The company had its own unique goal in the implementation of the Expo and-with or without controls-would have received direct blame for the event failure. Clearly, corruption scandals, media attention, an unescapable deadline, and substantial delays reinforced this mechanism. The threat to the ANAC self-interest needs further discussion.

The programme feature triggering the mechanism is the provision of mandatory controls for all contracting documents. Partly, this shifted the blame for the emergence of corruption from the mismanagement of Expo Ltd. to the accuracy of the controls performed by the ANAC. In 
addition, the mandatory controls also transferred part of the potential blame for delays. As mentioned, most observers interpreted the new procedure as a source of delays, and the ANAC certainly did not want to be pictured as the bureaucrat spoiling the event.

These programme features did not work alone, however. The perfect threat was created through a special combination of non-programme elements which reinforced the incentive provided by the design feature. First, the severe delays plaguing the event and the unescapable deadline for completing works demanded an exceptional effort from both the Unit and Expo Ltd. In this context, lengthening the time would have not produced ordinary red-tape inefficiencies, but a major international failure.

Second, corruption scandals and constant media attention put great pressure on the Authority. Working on the Expo permitted to link the ANAC - a formerly unknown administrative body - to the event with the greatest saliency in Italy's public life of those days. The Universal Exposition-its delays, scandals, future-made the news almost every day, several times a day. The ANAC was under the spotlight; it should balance accuracy and rapidity to avoid both future corruption and an immediate failure of the greatest international event organised in Italy in decades.

However, a third contextual feature is decisive in understanding why an implementation failure was considered so damaging for the ANAC and the Unit. It is worth reminding that the Milan Exposition was by no means an ordinary activity for the Authority. The ANAC originated from the transformation of a previous government agency - the Independent Commission for Evaluation, Transparency and Integrity (CIVIT) — created in 2009 for measuring the performance of public administrations. CIVIT added combating corruption to its duties only in 2012 and finally changed its name in October 2013 to become the ANAC. At that time, however, the agency was completely deadlocked; it lacked a President, its board counted only three out of five legal members required, and it was under-resourced in both personnel—only 30 officials_-and power, which was limited to advising public administrations in drafting their codes of conduct and anti-corruption plans. Part of the stalemate was resolved when a new President and board were appointed in March 2014 (Funzione Pubblica, 2014), but a complete transformation in powers and resources would come only two months later thanks to the Expo, which opened a window of opportunity for the development and institutionalisation of the Authority.

In May 2014, when the Prime Minister announced that the ANAC was going to be involved in controlling the Expo, the President of the Authority made clear that the resources of the ANAC did not allow for such controls: new powers and personnel were needed (Monaci \& Mincuzzi, 2014b). Soon after, law 90/2014 granted new powers (among which was collaborative surveillance), provided about 300 officials by merging a former public agency with the ANAC, and created the Unit.

The key role of the event in the institutionalisation of the Authority is confirmed by both official documents (ANAC, 2016d, p. 17) and our interviews with the President of ANAC (Personal communication, October 10, 2016). The Expo was the first and most important test for evaluating the renovated Authority and specifically the Unit-originally titled 'Special Operative Unit for Expo 2015'. Avoiding any possible blame for the event's failure was then a matter of organisational survival-a goal that certainly equalled that of preventing corruption.

\section{Repeated interactions}

Collaborative surveillance is an interesting oxymoron. It suggests that the organisation under surveillance (Expo Ltd.) collaborated with the controller (the Unit), who played the role of a 
partner and tutor more than external auditor. Given the statutory goal of preventing corruption and the context of general distrust in the Expo management, this collaboration was not expected to be easily implemented. In fact, the term collaborative surveillance was coined ex post-it does not appear in the law nor in the internal regulation of the Unit. The first mention of a possible collaborative approach to controls came only in December 2014 and was coined empirically when describing the activity in the first monitoring report by the OECD (OECD, 2015).

Indeed, the evolution of the relationship between the Unit and Expo Ltd. eventually led to their collaboration in terms of both their interactions and results. First, the interactions between the two completely changed over time. Imagine a special police force in charge of controlling an organisation with a procurement manager freshly arrested. The shadow of corruption loomed large over Expo Ltd. and the beginnings were hard. With some elements of caricature, Expo Ltd. describes the first exchanges as portraying a relationship more similar to 'cops and robbers' than implementation partners (Expo Ltd. Procurement Manager, personal communication, November 18, 2016). Soon, however, the 'forced interaction' deepened familiarity and trust and helped develop a more collaborative relationship, also testified by the use of the informal communication methods previously mentioned.

Table 1: Advices, observations, and accepted observations

\begin{tabular}{|l|l|l|l|l|l|}
\hline & $\mathbf{2 0 1 4}$ & $\mathbf{2 0 1 5}$ & $\mathbf{2 0 1 6}$ & $\mathbf{2 0 1 7}$ & Total \\
\hline Advices produced by the Unit & 65 & 213 & 42 & 7 & 327 \\
\hline $\begin{array}{l}\text { Observations on irregularities } \\
\text { and legal issues }\end{array}$ & 44 & 126 & 26 & 4 & 200 \\
\hline $\begin{array}{l}\text { Observations accepted by } \\
\text { Expo Ltd }\end{array}$ & 36 & 101 & 16 & 1 & 154 \\
\hline $\begin{array}{l}\text { Accepted observations / } \\
\text { Advices }\end{array}$ & 0.55 & 0.47 & 0.38 & 0.14 & 0.47 \\
\hline $\begin{array}{l}\text { Accepted observations / } \\
\text { Observations }\end{array}$ & 0.82 & 0.80 & 0.62 & 0.25 & 0.77 \\
\hline Observations / Advices & 0.68 & 0.59 & 0.62 & 0.57 & 0.61 \\
\hline
\end{tabular}

\section{Source: The Authors}

Second, and more importantly, this collaboration produced a substantive change in the quality of contracting. Table 1 reports all control activities performed for the event. It includes 174 procurement contracts that the Unit analysed, producing 327 pieces of advice (each contract comprises several contracting documents). Trends in the amount of advice and observations given by the Unit may say something about how this relationship developed. First, the quality of contracting by Expo Ltd. seemed to increase over time; in fact, the percentage of observations dropped from 2014 to 2015 and then stabilised, signalling an initial learning stage for the company. Second, the percentage of accepted observations constantly decreased with respect 
to both total observations and volume of advice. On the one hand, this can be interpreted as Expo Ltd.'s increased capacity to defend its decisions when confronting the Unit; on the other, the severity of observations by the Unit may have decreased over time. These interpretations are confirmed by interviews with the Unit members, who added that the observations on legal issues had become extremely rare over time, while most later observations tended to focus on matters of appropriateness in the use of the special powers that Expo Ltd. still enjoyed (Members of the Special Operative Unit, personal communication, October 25, 2016 and January 5, 2017; ANAC 2016c). These considerations certainly point to learning and an increased procurement capacity of Expo Ltd.

The mechanism explaining such an evolution is that of repeated interactions (see Figure 3). A cooperative behaviour is adopted because implementers learn to value relations and the costs of defecting are or become prohibitive. The mechanism works best the greater the interdependence of the actors and the frequency of their interactions (Busetti \& Dente, 2018).

Figure 3: Repeated interactions

\begin{tabular}{|c|c|c|}
\hline $\begin{array}{c}\text { Programme and non-programme } \\
\text { features increase the frequency of } \\
\text { interactions and interdependence of } \\
\text { actors }\end{array}$ & $\begin{array}{l}\text { Implementers start to } \\
\text { cooperate and value } \\
\text { their relation }\end{array}$ & $\begin{array}{c}\text { Implementation } \\
\text { outcome }\end{array}$ \\
\hline $\begin{array}{l}\text { PROGRAMME FEATURES: } \\
-\quad \text { Mandatory controls on all } \\
\text { documents for contracts }>€ 40,000 \\
\text { - } \text { Observations are not binding, but } \\
\text { Expo Ltd. is required to produce an } \\
\text { explanatory note } \\
\text { NON-PROGRAMME FEATURES: } \\
\text { - Organisational nature of Expo Ltd. }\end{array}$ & $\begin{array}{l}\text { - Adjustment to the Unit } \\
\text { requirements } \\
\text { - Reasoning and dialogue } \\
\text { on redrafting the } \\
\text { contracting documents }\end{array}$ & $\begin{array}{l}\text { - Learning by Expo } \\
\text { Ltd. } \\
\text { - Increased quality of } \\
\text { procurement }\end{array}$ \\
\hline
\end{tabular}

\section{Source: The Authors}

The first programme features activating the mechanism were the mandatory controls and the financial threshold. While avoiding overloading the Unit and Expo Ltd. by excluding minor contracts, the financial threshold left a considerable body of contracts to be controlled and hence produced the frequent interactions needed for the evolution of the collaboration. During the first five months of 2015, the most intense period, the Unit produced 129 pieces of advice in 140 days, or more than one per day (not counting Sundays) (ANAC, 2015b, p. 131). As shown in Table 1, the Unit issued 200 observations on 174 contracts and Expo Ltd. accepted 154 observations during the whole period.

These figures tell us two things. First, controls were neither formally applied nor circumvented. Indeed, an alternative explanation to the surprising effect of collaborative surveillance may well have been that controls were only formally applied; a symbolic policy to keep the works going. On the contrary-and this is the second point-it is exactly because controls were pervasive and interactions frequent that the mechanism was activated.

To fully appreciate the intensity of this relation, it is worth remembering that every piece of advice starts a dialogue between the Unit and Expo Ltd. To give only one example, in the first year of activity-from May 2014 to May 2015-the Unit produced 194 pieces of advice, of which 138 came with observations. Expo Ltd. did not automatically accept or refuse the observations; it elaborated 119 counter-observations, which started a dialogue that eventually led to the ac- 
ceptance of 99 observations (ANAC, 2015b, p. 131). This takes us to the second design feature triggering the mechanism: the fact that the comments are not binding but a refusal should be motivated. This forced Expo Ltd. to discuss the logic behind the comments and analyse the accuracy of the original contracting documents to decide whether to redraft the document or go forward and explain its decisions. This dialogue between the controller and the controlled was central to learning.

However, these programme features were complemented by a fundamental contextual condition. When describing the success of collaborative surveillance in his book, the President of ANAC said that working in Milan made a significant difference for the success of what he called 'the Expo model' (Cantone, 2015). As further explained in a personal communication, by this he meant that the Unit had a counterpart that greatly facilitated their job (President of ANAC, personal communication, October 10, 2016). In fact, Expo Ltd. was a small organisation made up of a handful of skilled and motivated professionals. Not only were they quick to adjust to the Unit's requirements and change their working methods, but such a small organisation was able to provide a unique point of contact with the Unit and hence help establish a direct bilateral dialogue. Briefly put, the nature of the controlled organisation was crucial to the success of the controller.

\section{Actor certification}

We have seen that controls were implemented quickly and that the quality of contracting increased. Although important, these results did not change the nature of preliminary controls: an additional burden that required almost half of the documents to be rewritten (see Table 1), in most cases after having produced counter-observations. In this respect, the most contradictory result concerns the statements from the interviews (Members of the Special Operative Unit, personal communication, October 25, 2016 and January 5, 2017; Expo Ltd. Procurement Manager, personal communication, November 18, 2016) and the scientific papers by the ANAC (Luongo, 2019), whose controls actually sped up the tendering process.

In order to understand this outcome, we should redirect our attention away from the bilateral relation between the Unit and Expo Ltd. In fact, the procurement and execution of contracts depended on two other players: the contractors and the administrative judges. Both could severely delay and sometimes completely disrupt implementation.

First, when the contracts were awarded, losing companies could appeal to the administrative court for alleged irregularities. The judgement might determine to change the contractor and the parties could respond by requiring a second trial to a second-order court. These appeals and the possible replacement of the winner could be a tremendous source of delay. Interestingly, when the ANAC entered the game, appeals - which did happen for some of the Expo 2015 contracts before-dropped dramatically, even reaching zero (Members of the Special Operative Unit, personal communication, October 25, 2016 and January 5, 2017; Expo Ltd. Procurement Manager, personal communication, November 18, 2016; Luongo, 2019). The most plausible explanation is that when adjudications were reviewed by the Unit, the losing companies considered it harder to start a judicial challenge. The same went for the administrative courts, which - if they accepted the appeals from losing companies—should have gone against what had already been reviewed and approved by the ANAC. In both cases, the procedures controlled by the Unit appeared to be 'reinforced'.

A test for the relative strength of decisions taken by the ANAC occurred right at the start, with a row over the contract for service infrastructures (the one that opened the scandals). When 
corruption emerged, the Lombardy Administrative Court received and accepted the appeal by the company ranked second in the tender assessment. The Court decided in favour of the company and mandated Expo Ltd. to replace the former winner, who had been accused of corruption. In the meantime, the ANAC entered the Expo procurement and proposed to subject the contract in question to a special procedure of confiscation, in which the ANAC could appoint a Special Commissioner to run the works without replacing the accused company. The secondorder Court eventually agreed with the solution proposed by the ANAC. Although this decision entailed a procedure different from collaborative controls, it signalled the centrality of the ANAC for the Expo procurement. No other appeals would be attempted against any procedures activated or reviewed by the ANAC.

The other advantage concerned the relation between Expo Ltd. and the contractors. Interviews show that the controls and recommendations by the ANAC were used strategically by Expo Ltd. to resist pressure to use special powers and implement more discretionary tendering procedures (Expo Ltd. Procurement Manager, personal communication, November 18, 2016). Especially in a case such as the Expo, where the contracting authority enjoyed wide-ranging special powers, having an external constraint could in fact be more of a benefit than a burden. A telling example comes from a dispute between Expo Ltd. and the three-time Academy Award winner Dante Ferretti, who was commissioned to do a series of statues and sculptures decorating public spaces on the event site. Expo Ltd. imposed a stricter specification of the bid by strategically using the constraints imposed by the ANAC, hence requiring a longer time to prepare the bid and eventually starting a dispute on the timely realisation of the works. Overall, by being backed by the ANAC, the ability of Expo Ltd. to resist pressures to use its special powers certainly increased (Luongo, 2019).

In all the above cases, the explanation lies in the activation of a mechanism called 'actor certification' (Barzelay, 2007; Melloni 2013). Certification entails the validation of actors, their performances, and their claims by external authorities (McAdam et al., 2001). This takes place when an implementer is endorsed by another actor who is considered particularly worthy because of its technical skills, past achievements, political standing, and so forth (Busetti \& Dente, 2018). The activation of the mechanism implies a source of certification and the recognition of the value of such certification by implementers. Figure 4 illustrates this mechanism.

Figure 4: Actor certification

\begin{tabular}{|c|c|c|}
\hline $\begin{array}{c}\text { Programme and non-programme } \\
\text { features provide a source of } \\
\text { certification }\end{array}$ & $\begin{array}{c}\text { Implementers recognise } \\
\text { certification }\end{array}$ & $\begin{array}{l}\text { Implementation } \\
\text { outcome }\end{array}$ \\
\hline $\begin{array}{l}\text { PROGRAMME FEATURES: } \\
\text { - } \quad \text { Mandatory controls on all } \\
\text { documents for contracts }> \\
\text { E40,000 } \\
\text { - } \quad \text { The Unit is made of police } \\
\text { officers part of the Financial } \\
\text { Police } \\
\text { NON-PROGRAMME FEATURES: } \\
\text { - Personal reputation enjoyed } \\
\text { - } \text { by the President of ANAC } \\
\text { Direct political backing by the } \\
\text { - } \quad \text { Prime Minister } \\
\text { Endorsement by the OECD }\end{array}$ & $\begin{array}{l}\text { - Losing companies prefer } \\
\text { not to appeal to } \\
\text { administrative courts } \\
\text { - Expo Ltd. uses ANAC } \\
\text { strategically to resist } \\
\text { pressures }\end{array}$ & $\begin{array}{l}\text { - Greater speed in } \\
\text { contract } \\
\text { implementation }\end{array}$ \\
\hline
\end{tabular}


We have already seen that implementers value certification: Expo Ltd. used it productively to resist pressure and the losing companies stopped making appeals. The source of certification deserves further analysis.

The more obvious programme feature activating the mechanism is certainly the procedure of controls; it is through controls that certification is transferred from the ANAC to Expo Ltd. The second programme feature involves the composition of the Unit: police officers who take a tough 'investigative' approach to controls. This certainly provides credibility and hence certification well beyond ordinary administrative controls. Finally, there are three context features that need to be considered.

First, the then President of the ANAC was not an ordinary bureaucrat. He was a high-flyer with a brilliant reputation and some fame for his job as a magistrate fighting organised crime. After his years in the investigative branch of the judiciary, he worked in an administrative post and began counselling governments on the topics of corruption and organised crime. He was present in the media and known to the public; a 'legality popstar' whose name was invoked for almost all kinds of public posts, from mayor to President of the Republic (Fattorini, 2017).

Second, at the time of the Expo, the ANAC and its President enjoyed a very special political backing directly from the Prime Minister. Not only was it the Prime Minister himself that had appointed the President of the ANAC and decided to involve the ANAC in controlling the Expo, but throughout his mandate, whenever it came to listing the results of his government, he mentioned the ANAC on almost all public occasions, always presenting the Authority's activities as best practices. It was no coincidence that when invited to dine at the White House for the last state dinner of President Barack Obama, the Prime Minister took with him a small group of 'Italian excellences', among whom were the President of the ANAC (Martini, 2016).

Finally, the ANAC actively searched for external endorsement by signing a Memorandum of Understanding with the OECD. This was meant to produce technical feedback on collaborative surveillance through the periodic monitoring of its implementation and effects. Clearly, it was also a tool to increase the recognition of the ANAC as a reliable player. The Authority was new and was implementing a completely innovative procedure for controls. In this respect, the involvement of the OECD worked as a quality assurance for the system: a certification of the certifier.

\section{A unique experiment?}

Collaborative controls were immediately replicated and eventually institutionalised in 2016, when they were incorporated into the Code of Public Procurement and the Unit became permanent. Already in August 2015, the government decided to extend the collaborative surveillance to the procurement process for the Extraordinary Jubilee of Mercy to be held in Rome between 2015 and 2016 (ANAC, 2015a). In 2016, three applications followed: the regeneration of a large industrial area in Naples (Presidenza del Consiglio, 2016), the reconstruction following a major earthquake in Central Italy (ANAC, 2016a), and a selection of procurement contracts of the city of Reggio Calabria, which was considered at risk of pressures by organised crime (ANAC, 2016b). In 2018, the controls were applied to the contracts of the 2019 World Summer University Games (to be held in Naples) and to those for the Italian pavilion and related events for the Expo Dubai 2020.

These cases have much in common. Most of them apply to special events managed by contracting authorities that have the liberty to implement out-of-the-ordinary procedures and have 
an exceptional budget. Some even share a similar context of corruption scandals and lack of trust in the public administration: the Jubilee followed a corruption scandal that gained incredible media attention, while earthquake reconstructions have a history of mismanagement and easily generate public alarm. Although these replications appear as a homogeneous selection, similarities should be evaluated in causal terms-i.e., by examining whether the original mechanisms apply outside the special context of the Expo and whether some elements can work as the functional equivalents of those that are necessary but missing. In the remainder of the section, we will analyse the three mechanisms in turn.

Threat attribution is difficult to replicate with the same intensity as at the Expo. The constant media attention enjoyed by the Universal Exposition and the continuous debate over the delays that were going to spoil the event have no equal in subsequent applications. Similarly, by being the first experiment of collaborative controls, the Expo certainly enjoyed additional commitment and held symbolic value for the ANAC, thereby increasing the threat of a possible failure. However, most replications have something in common that may help conserve the mechanism and reinforce the effect of design features. Most cases require a quick delivery, either because they have a proper deadline (the World University Games, the Jubilee, or the contracts for the Dubai Expo) or because they are known to the public and delays will periodically catch media attention (the post-earthquake reconstruction and partly the regeneration of the industrial site in Naples). These conditions may constitute an important incentive for the Unit to deliver their advice quickly. In fact, in a simplistic interpretation of controls, newspapers attributed delays to the supposed bureaucracy of the ANAC, hence transferring the responsibility from the contracting authority to the Unit, which produced an incentive to maintain the initial performance (e.g., Gentile, 2018). Indeed, if one looks at the Unit performance data in 2018 (when controls on the Expo contracts ended) against an increase in the volume of advice, the Unit kept delivering controls within 3 days on average, well below the legal requirement (ANAC, 2019, p. 264).

However, the same argument does not apply to the contracting authority. In fact, the lack of exceptional contextual conditions pertaining to the Expo-daily media attention, a procurement manager arrested, a single-task organisation, a truly inescapable deadline-may have been irreplaceable. For the contracting authorities, in fact, ex-ante controls may even have diluted responsibility and hence hindered the timely implementation of procurement documents. One possibility would have been to design a transparent system for monitoring procurement, which may have helped attribute responsibility and create some threat. As discussed below, however, this should have been complemented with an organisational structure that clearly identifies responsibilities within the contracting administration. If not, transparency may have been of little use in 'threatening' the contracting authority.

The mechanism of repeated interaction is possibly the most fragile. In the source case, learning and the increase in the quality of contracting derived from the frequency of interaction coupled with a specific capacity of the contracting authority-i.e., its ability to adjust to the Unit's requirements and actively examine how to redraft contract documents. Concerning frequency, one may only need to be careful in selecting a number of documents to ensure frequent interactions without overloading the Unit and the controlled administration. This is an example of a programme feature that can easily 'travel' across cases but may need some simple fine-tuning, such as a re-modulation of the number of contracts exempted from controls.

However, the main difficulty with recreating repeated interactions consists in the characteristics of the controlled administration. Small, competent, and committed bodies which concen- 
trate all procurement decisions are not easily found; the exception are perhaps truly special events, such as the World University Games, which seem to reproduce the same interactions found in the case of the Expo (ANAC, 2019). For the Jubilee of Mercy and the post-earthquake reconstruction, these conditions were not met. The Jubilee was managed by a special office within the Rome municipality, which only had coordination functions but no contracting power. Furthermore, the earthquake involved four regions, different regional offices for coordination, and several contracting authorities at the local level. The fragmentation of responsibilities resulted in a major change in the performance of collaborative controls, decreasing the ability of the Unit to influence the contracting and generate learning (members of the Special Operative Unit, personal communication, October 25, 2016 and January 5, 2017; ANAC, 2018, 2019).

In redesigning controls, the ANAC should consider the capacity of the controlled bodies and fine-tune future controls by ensuring they have the appropriate characteristics for triggering repeated interactions and hence learning. This is obviously difficult. For each new collaborative surveillance, the ANAC signs an agreement establishing the rules of conduct and specifying how communication should be managed between the Unit and the controlled administration. These agreements may vary, but functional equivalents that are easy to imagine- such as the concentration of responsibilities for all procurement-may face obvious resistance and may be difficult or simply impossible to impose (as in the case of an earthquake affecting multiple regions). However, the Unit should examine these issues carefully when activating new controls, discuss them with the controlled administration and-when possible-avoid cases where no learning is to be expected. This is important, since the quality of the procurement does not depend only on the review done by the Unit or on the rate of acceptance of observations but also on the contracting authority which actively works in drafting and correcting documents.

Finally, certification is the mechanism more easily conserved across changing circumstances. The ex-ante controls by an investigative military unit will certainly keep providing some certification notwithstanding the context. In addition, although they cannot be assumed as constant, all the non-programme features supporting the mechanism can be controlled by the ANAC. In the case of the Expo, these features included the profile of the President, the direct political backing, and the collaboration with the OECD.

During the Expo, ANAC's reputation was at its peak: it had the strongest political support ever and kept increasing in notoriety by being involved in all the difficult cases of the government of that time (e.g., a major bond mismanagement by banks and the corruption scandal over the project of flood barriers for the Venice Lagoon). This honeymoon effect is typical for new agencies but does not last (Boin \& Christensen, 2008). The analysis provided here suggests that maintaining reputation should be a central worry for the Authority not simply as a general resource, which is always good to have, but precisely for maintaining the effectiveness of collaborative controls. In the absence of spontaneous support, the ANAC should search for functional equivalents to balance the possible decrease in reputation. This search may entail finding new allies in a way similar to what was done with the OECD-i.e., ensuring its decisions obtain the endorsement of external actors. One example of this strategy is the implementation of the 2016 Code of Public Procurement, wherein the ANAC was in charge of providing guidelines for implementing several parts of the Code. In issuing such guidelines, the ANAC always asked the 'Consiglio di Stato' (the highest Administrative Court) for its judgement and counsel (ANAC, 2017a). This is not only a way of avoiding turf wars but also another form of certification of the certifier. 


\section{Conclusions}

As suggested by extrapolation-oriented studies, an attention to the causal mechanisms is fundamental for explaining how outcomes are produced. The risk of spurious attribution, the overestimation of the power of designs, or reducing the entire explanation to very special contextual conditions are typical problems in understanding policy success. An explicit focus on the causal mechanisms may help identify which features are relevant and how they combine to produce outcomes.

This knowledge is the starting point for both reforming and designing programmes. It cannot be used for understanding typical cases or to explain average dynamics-i.e., how corruption controls usually work. Instead, it provides a model for future applications embodying the same mechanisms. Although variation across cases is commonplace, having a causal model of the programme is a starting point for designers in the search of reproducing the same outcome obtained in the original exemplar. It serves for both estimating the prospects for 'conserving' mechanisms across cases and (re)designing in the face of changing circumstances.

Concerning the first point-the portability of mechanisms - there can be cases of complete contextual dependence, cases so special that they work only at a specific time and place. However, notice that we presented a very special case: a major corruption scandal, a unique megaevent, a brand-new anti-corruption authority, and a pilot system of controls. Nevertheless, the lessons from this case are not limited to the Expo. Not only there is a 'subpopulation' of cases where the original causality is maintained (notably, the World University Games or future Expos), but some variation is tolerable and does not impede the replication of positive outcomes.

The second point follows suit. The applicability of these mechanisms is not entirely 'natural'; it is partly a matter of design. Future applications may require the introduction of functional equivalents, disregard some of the original elements or fine-tune designs to changing circumstances. This redesigning may be costly and sometimes impossible, but unless designers have a proper causal model of the original exemplar, they do not even have a starting point. Having a clear picture of the causality of the programme is the only way to reproduce the same outcomes in different places and across different target populations instead of surrendering to context dependency.

In conclusion, three complementary paths for future research should be mentioned. One is the need to 'discover' new mechanisms with the ambition of building a catalogue that may enrich the designer's toolkit. This is no easy task. As observed by one reviewer, this research agenda has surfaced intermittently during the last two decades but without significant innovation in the mechanisms used by researchers. The reasons for this lack of success are hard to pinpoint, but some suggestions can be put forward.

Discovering new mechanisms requires empirical investigations based on research-intensive case studies that take an extrapolative orientation towards explaining relevant outcomes. This search demands for specificity in identifying both the causal elements composing the hypothesised mechanism and their interaction into consistent causal configurations. This has not been done so far, or at least not enough.

Instead, references to mechanisms have been rather intuitive or metaphorical, in some cases providing labels for causal processes that remained largely unspecified. The very definition of mechanisms is uncertain and not yet established, with scholars suggesting examples as varied (and ambiguous) as power (Rueschemeyer, 2009) or coordination (Falleti and Lynch, 2009). 
Such problems may have prevented a wider appeal of the mechanisms' agenda, and the suggestion can only be to work for greater rigor and specificity in opening the black box of those causal processes that are to be labelled as mechanisms.

Notice, however, that there is no theoretical justification for mechanisms to be large in number. Actors in policymaking, implementers and target groups do not change their behaviour in response to policy for an infinite number of reasons. The design elements triggering behavioural change may certainly be vast in number and varied in nature, but the underlying causal mechanisms need not be. Therefore, a second path for future research is to deepen our knowledge of the several ways by which different design elements may trigger mechanisms, both old and new.

Finally, the third path is methodological. There are specific methods, such as process tracing, that promise to identify mechanisms in a rigorous way. These methods may help in identifying the design elements triggering change and in understanding the causal model to be reproduced in future applications. Unfortunately, however, we do not have any guidelines on how designs can be adjusted across cases-i.e., when and how to introduce functional equivalents-or when new cases are to be considered unfit to the replication of a certain mechanism. A similar investigation would be of great use to those who want to learn from existing programmes with the purpose of designing new ones.

\section{Bibliography}

\section{List of interviews}

- Special Commissioner for the canal system of the Expo, December 20, 2016

- Special Commissioner for the service infrastructures of the Expo, December 15, 2016

- President of the ANAC, personal communication, October 10, 2016

- Members of the Special Operative Unit, October 25, 2016

- Members of the Special Operative Unit, January 5, 2017

- Expo Ltd. Procurement Manager, November 18, 2016

ANAC. (2014a). Linee guida per l'esercizio dei compiti di alta sorveglianza e di garanzia della correttezza e della trasparenza delle procedure connesse alla realizzazione delle opere e delle attività connesse allo svolgimento del grande evento Expo Milano 2015 [Guidelines for anti-corruption controls of activities and infrastructures connected to the Milan Expo 2015]. Retrieved from: http://www.anticorruzione.it/portal/rest/jcr/repository/collaboration/Digital\%20Assets/ANACdocs/Attivita/Expo2015/LINEE-GUIDA-ANAC-17-7-2014.pdf

ANAC. (2015a). Linee guida per l'esercizio dei compiti di alta sorveglianza e di garanzia della correttezza e della trasparenza delle procedure connesse alla realizzazione delle opere e delle attività connesse allo svolgimento del giubileo straordinario della misericordia [Guidelines for anti-corruption controls of activities and infrastructures connected to the Extraordinary Jubilee of Mercy]. Retrieved from: http://www.anticorruzione.it/portal/rest/jcr/repository/collaboration/Digital\%20Assets/ANACdocs/Attivita/Atti/Giubileo/LineeGuidaGiubileo.08.09.15.pdf 
ANAC. (2015b). Relazione annuale 2014 [2014 Activity Report]. Retrieved from:

http://www.anticorruzione.it/portal/rest/jcr/repository/collaboration/Digital\%20Assets/anacdocs/Attivita/Pubblicazioni/RelazioniAnnuali/2015/ANAC.Relazione.2014.02.07.15.pdf

ANAC. (2016a). Monitoraggio e vigilanza collaborativa sugli interventi di emergenza conseguenti al sisma che il 24 agosto 2016 ha colpito i territori delle regioni Abruzzo, Lazio, Marche e Umbria [Guidelines for anti-corruption controls for the post-earthquake reconstruction in Abruzzo, Lazio, Marche and Umbria]. Retrieved from:

http://www.anticorruzione.it/portal/rest/jcr/repository/collaboration/Digital\%20Assets/ANACdocs/Attivita/ProtocolliIntesa/2016/prot.sisma.regioni.26.10.16.pdf

ANAC. (2016b). Protocollo di azione vigilanza collaborativa tra Autorità Nazionale Anticorruzione, Prefettura, procura della repubblica presso il tribunale di Reggio Calabria e comune di Reggio Calabria [Agreement between ANAC, 'Prefettura', and 'Procura' for delivering anti-corruption controls of the municipality of Reggio Calabria]. Retrieved from:

http://www.prefettura.it/reggiocalabria/allegati/Download:Protocollo_di_azione_vigilanza_collaborativa_tra_autorita_nazionale_anticorruzione_prefettura_procura_della_repubblica_presso_ il_tribunale_di_reggio_calabria_e_comune_di_reggio_calabria-5709048.htm

ANAC. (2016c). Relazione annuale 2015 [2015 Activity Report]. Retrieved from:

http://www.anticorruzione.it/portal/rest/jcr/repository/collaboration/Digital\%20Assets/ANACdocs/Attivita/Pubblicazioni/RelazioniAnnuali/2016/ANAC.relazione2015.14.07.16.pdf

ANAC. (2016d). Piano di Riordino [Reorganisation plan]. Retrieved from:

http://www.anticorruzione.it/portal/rest/jcr/repository/collaboration/Digital\%20Assets/ANACdocs/Attivita/PianoRiordino/PianoRiordinoANAC.accessibile.pdf

ANAC. (2017a). Relazione annuale 2016 [2016 Activity Report]. Retrieved from:

https://www.anticorruzione.it/portal/rest/jcr/repository/collaboration/Digital\%20Assets/anacdocs/Attivita/Pubblicazioni/RelazioniAnnuali/2017/rel.anac.2016.doc.06.07.2017_.pdf

ANAC. (2017b). Regolamento sull'esercizio dell'attività di Vigilanza collaborativa in materia di contratti pubblici [Regulation on collaborative controls for public procurement]. Retrieved from:

http://www.anticorruzione.it/portal/public/classic/AttivitaAutorita/AttiDellAutorita/_Atto?id=4 1f61fdc0a778042608be88c009a699f

ANAC. (2018a). Relazione annuale 2017 [2017 Activity Report]. Retrieved from:

http://www.anticorruzione.it/portal/rest/jcr/repository/collaboration/Digital\%20Assets/anacdocs/Attivita/Pubblicazioni/RelazioniAnnuali/2018/ANAC.Relazione.2018(1).pdf

ANAC. (2018b). Accordo per l'esercizio dei compiti di alta sorveglianza e di garanzia della correttezza e della trasparenza delle procedure connesse alla Universiade Napoli 2019 [Agreement for de livering anti-corruption controls of the 2019 World University Games]. Retrieved from:

http://www.anticorruzione.it/portal/rest/jcr/repository/collaboration/Digital\%20Assets/anacdocs/Attivita/ProtocolliIntesa/2018/Acc.vigilanzaUniversiade2019.pdf

ANAC. (2018c). Protocollo di vigilanza collaborativa per la partecipazione italiana a expo 2020 Dubai [Agreement for delivering anti-corruption controls for the Italian participation to the 2020 Dubai Expo]. Retrieved from:

https://www.anticorruzione.it/portal/rest/jcr/repository/collaboration/Digital\%20Assets/anacdocs/Autorita/UnitaOperativaSpec/Prot.Vig.ExpoDubai12.10.2018\%20(1).pdf

ANAC. (2019). Relazione annuale 2018 [2018 Activity Report]. Retrieved from: http://www.anticorruzione.it/portal/rest/jcr/repository/collaboration/Digital\%20Assets/anacdocs/Attivita/Pubblicazioni/RelazioniAnnuali/2019/000.ANAC.RELAZIONE.PARLAMENTO.2019.pdf 
ANAC-OECD. (2014). Memorandum of understanding for cooperative activities for EXPO 2015. Retrieved from:

http://www.anticorruzione.it/portal/rest/jcr/repository/collaboration/Digital\%20Assets/ANACdocs/Attivita/ProtocolliIntesa/Memorandum-of-Undestranding-ANAC-OCSE-signed-03-10-2014. pdf

ANAC-OECD. (2015). 'High Level Principles' for integrity, transparency and effective control of major events and related infrastructures. Retrieved from:

http://www.oecd.org/gov/ethics/High-Level_Principles_Integrity_Transparency_Control_Events_ Infrastructures.pdf

Anechiarico, F., \& Jacobs, J. B. (1998). The pursuit of absolute integrity: How corruption control makes government ineffective. Chicago, IL: University of Chicago Press.

Barbacetto, G., \& Maroni, M. (2015, April 18). Expo 2015, tre opere su quattro ancora incomplete e senza collaudi [2015 Expo: three works out of four are incomplete]. Fatto Quotidiano. Retrieved from: http://www.ilfattoquotidiano.it/2015/04/18/expo-2015-3-opere-4-incomplete-collaudi/1603108/

Bardach, E. (2004). The Extrapolation Problem: How Can We Learn from the Experience of Others? Journal of Policy Analysis and Management, 23(2), 205-220.

Barzelay, M. (2007). Learning from Second-Hand Experience: Methodology for Extrapolation-Oriented Case Research. Governance, 20(3), 521-543.

Beach, D., \& Pedersen, R. B. (2019). Process-tracing methods: Foundations and guidelines. Ann Arbour, MI: University of Michigan Press.

Biondani, P., \& Gatti, F. (2014, May 14). Expo, cronaca di uno scandalo annunciato [2015 Expo : Chronicles of a scandal foretold].L'Espresso. http://espresso.repubblica.it/plus/articoli/2014/05/14/ news/expo-cronaca-di-uno-scandalo-annunciato-1.165444

Boin, A., \& Christensen, T. (2008). The development of public institutions: Reconsidering the role of leadership. Administration \& Society, 40(3), 271-297.

Bozeman, B. (1993). A theory of government "red tape". Journal of public administration research and theory, 3(3), 273-304.

Bozeman, B., Reed, P. N., \& Scott, P. (1992). Red tape and task delays in public and private organizations. Administration \& Society, 24(3), 290-322.

Bramwell, B. (1997). Strategic planning before and after a mega-event. Tourism Management, 18(3), 167-176.

Busetti, S., \& Dente, B. (2018). Designing multi-actor implementation: A mechanism-based approach. Public Policy and Administration, 33(1), 46-65.

Cantone R., \& Di Feo, G. (2015). Il male italiano: liberarsi dalla corruzione per cambiare il paese [The Italian Evil: how to change the country by eliminating corruption]. Milano: BUR.

Capano, G., Howlett, M., Ramesh, M., \& Virani, A. (Eds.). (2019). Making Policies Work: First-and Second-order Mechanisms in Policy Design. Cheltenham: Edward Elgar Publishing.

Capano, G., \& Howlett, M. (2019). Causal logics and mechanisms in policy design: How and why adopting a mechanistic perspective can improve policy design. Public Policy and Administration. https://doi.org/10.1177/0952076719827068

Falleti, T. G., \& Lynch, J. F. (2009). Context and causal mechanisms in political analysis. Comparative political studies, 42(9), 1143-1166. 
Fattorini, M. (2017). Ecco chi è Raffaele Cantone, la popstar della legalità [Raffaele Cantone : A legality popstar]. Linkiesta. http://www.linkiesta.it/it/article/2017/03/27/ecco-chi-e-raffaele-cantonela-popstar-della-legalita/33675/

Franzese, R. J. (2007). Multicausality, Context-Conditionality, and Endogeneity. In C. Boix \& S. C. Stokes (Eds.), The Oxford handbook of comparative politics. Oxford Handbooks Online.

Funzione Pubblica. (2014). Avvicendamento al vertice dell'autorità anticorruzione [New Leadership at ANAC]. Retrieved from:

http://www.funzionepubblica.gov.it/articolo/ministro/23-04-2014/avvicendamento-al-verticedell\%E2\%80\%99autorita-anticorruzione

Gerring, J. (2006). Case study research: Principles and practices. New York, NY: Cambridge University Press.

Gerring, J. (2010). Causal Mechanisms: Yes, but.... Comparative Political Studies, 43(11), 1499-1526.

Gentile, C. (2018, March 4). Dai parchi alle aiuole niente manutenzione la città è una giungla. Bloccati dall'Anac gli appalti che dovevano archiviare l'era Buzzi [ANAC is blocking the contracts that had to surpass Mafia Capitale]. La Repubblica. Retrieved from: https://roma.repubblica.it/cronaca/2018/05/04/news/roma_dai_parchi_alle_aiuole_niente_manutenzione_la_citta_e_una_giungla-195472515/?refresh_ce

Gursoy, D., \& Kendall, K. W. (2006). Hosting mega events: Modeling locals' support. Annals of Tourism Research, 33(3), 603-623.

Hedström, P., \& Swedberg, R. (Eds). (1998). Social Mechanisms: An Analytical Approach to Social Theory. Cambridge: Cambridge University Press.

Kang, Y., \& Perdue, R. (1994). Long-term impact of a mega-event on international tourism to the host country: a conceptual model and the case of the 1988 Seoul Olympics. Journal of International Consumer Marketing, 6(3-4), 205-225.

Luongo, T. (2019). L’Unità Operativa Speciale dell'ANAC [The Special Operative Unit]. ANAC. Retrieved from:

http://www.anticorruzione.it/portal/rest/jcr/repository/collaboration/Digital\%20Assets/anacdocs/Attivita/Pubblicazioni/Collana\%20scientifica\%20Autorita/LUONGO\%20DocumentoFinale\%206\%20giugno\%202019.pdf

Martini, F. (2016, October 19). Alla Casa Bianca va in tavola la cena di Stato, con Renzi e Obama oltre 400 ospiti [State dinner at the white house, with the PM Renzi, Barack Obama and other 400 guests]. La Stampa. Retrieved from:

http://www.lastampa.it/2016/10/19/esteri/alla-casa-bianca-va-in-tavola-la-cena-di-stato-con-renzi-e-obama-oltre-ospiti-q7AlS0ac3DmUuAljDkZR8J/pagina.html

Mayne, J. (2012). Contribution analysis: Coming of age? Evaluation, 18(3), 270-280.

Mayntz, R. (2004). Mechanisms in the analysis of social macro-phenomena. Philosophy of the Social Sciences, 34(2), 237-259.

McAdam, D., Tarrow, S., \& Tilly, C. (Eds). (2001). Dynamics of Contention. New York, NY and Cambridge: Cambridge University Press.

Melloni, E. (2013). Ten Years of European Impact Assessment: How It Works, for What and for Whom. World Political Science, 9(1), 263-290. 
Monaci, S. (2014, May 1). Expo 2015, corsa contro il tempo: metà delle opere è in ritardo [Running against time : half the Expo contracts are in delay]. Il Sole 24 Ore. Retrieved from: http://www.ilsole24ore.com/art/notizie/2014-05-01/corsa-contro-tempo-l-expo-063843. shtml?uuid=ABGJU1EB

Monaci, S., \& Mincuzzi, A. (2014, May 17). Cantone sull'Expo: «non faccio gite a Milano, servono più poteri [Cantone on the Expo : I won't go to Milan for tourism, more powers are needed]. Il Sole 24 Ore. Retrieved from:

http://www.ilsole24ore.com/art/notizie/2014-05-17/affondo-cantone-expo-081324.shtml

OECD. (2015a). Report on the governance model and on the methodology. Retrieved from:

http://www.anticorruzione.it/portal/rest/jcr/repository/collaboration/Digital\%20Assets/ANACdocs/Attivita/Expo2015 /ANAC.ocse.report.pdf

OECD. (2015b). Second interim report. Retrieved from:

https://www.anticorruzione.it/portal/rest/jcr/repository/collaboration/Digital\%20Assets/anacdocs/Attivita/Expo2015/ANACReportENG.pdf

OECD. (2015c). High-level principles for integrity, transparency and effective control of major events and related infrastructures. Retrieved from:

http://www.oecd.org/gov/ethics/High-Level_Principles_Integrity_Transparency_Control_Events_ Infrastructures.pdf

OECD. (2015d). Effective Delivery of Large Infrastructure Projects: The Case of the New International Airport of Mexico City. Retrieved from:

https://www.oecd.org/gov/effective-delivery-of-large-infrastructure-projects-9789264248335-en. htm

OECD. (2016). First Progress Report on the development of the New International Airport of Mexico City Towards Effective Implementation. Retrieved from:

https://www.oecd.org/governance/ethics/progress-report-new-airport-mexico-city.pdf

Pandey, S. K., \& Scott, P. G. (2002). Red tape: A review and assessment of concepts and measures. Journal of public administration research and theory, 12(4), 553-580.

Pillay, U., Tomlinson, R., \& Bass, O. (2009). Development and dreams: the urban legacy of the 2010 Football World Cup. Cape Town: HSRC Press.

Poletti, F. (2015, April 1). Manca un mese all'avvio dell'Expo, in ritardo tre cantieri su Quattro [One month to the Expo opening and three infrastructures over four are in delay]. LaStampa. Retrieved from: http://www.lastampa.it/2015/04/01/italia/cronache/manca-un-mese-allavvio-dellexpo-in-ritardotre-cantieri-su-quattro-OVyP4iR7ZH7KwwfWmR8j9M/pagina.html

Presidenza del Consiglio dei Ministri. (2016). Protocollo di vigilanza collaborativa sulle procedure connesse alla realizzazione della bonifica ambientale e rigenerazione urbana dell'area di rilevante interesse nazionale Bagnoli-Coroglio [Agreement for delivering anti-corruption controls for the regeneration of the former industrial area of Bagnoli-Coroglio]. Retrieved from: http://www.anticorruzione.it/portal/rest/jcr/repository/collaboration/Digital\%20Assets/ANACdocs/Attivita/ProtocolliIntesa/prot.PdCM.Bagnoli.24.05.16.pdf

Rose, R. (1993). Lesson-drawing in public policy: A guide to learning across time and space (Vol. 91). Chattam, NJ: Chatham House Publishers.

Rose-Ackerman, S., \& Palifka, B. J. (2016). Corruption and government: Causes, consequences, and reform. Cambridge: Cambridge University Press. 
Rueschemeyer, D. (2009). Usable theory: Analytic tools for social and political research. Princeton, NJ: Princeton University Press.

Spilling, O. R. (1996). The entrepreneurial system: On entrepreneurship in the context of a megaevent. Journal of Business Research, 36(1), 91-103.

Steel, D. (2007). Across the boundaries: Extrapolation in biology and social science. Oxford: Oxford University Press.

Stevens, T., \& Bevan, T. (1999). Olympic legacy. Sport Management, 19(9), 16-19.

Tsebelis, G. (2002). Veto players: How political institutions work. Princeton, NJ Princeton University Press.

Verdelli,C.(2015,Apri19).Lacorsacontroiltemponeicantieridell'Expo21giornipersalvarel'immagine dell'Italia [Race against time in the Expo : 21 days to save the event]. La Repubblica. Retrived from: http://ricerca.repubblica.it/repubblica/archivio/repubblica/2015/04/09/la-corsa-contro-il-temponei-cantieri-dellexpo-21-giorni-per-salvare-limmagine-dellitalia22.html?ref=search 